2. Pearson GD, Kan JS, Neill CA, Misgley FM, Gardner TJ, Hougen TJ. Cervical aortic arch with aneurysm formation. Am J Cardiol. 1997;79: 112-4.

3. Farsak B, Yilmaz M, Kaplan S, Boke E. Cervical aortic arch with aneurysm formation. Eur J Cardiothorac Surg. 1998;14:437-9.
4. Davidovic LB, Markovic DM, Pejkic SD, Kovacevic NS, Colic MM, Doric PM. Subclavian artery aneurysms. Asian J Surg. 2003;26:7-11.

5. Tsukamoto O, Seto S, Moriya M, Yano K. Left cervical aortic arch associated with aortic aneurysm and coartation, and branch artery aneurysm: a case report and review. Angiology. 2003;54:257-60.

\title{
A successful total cavopulmonary connection conversion 13 years after an anatomic repair for tricuspid atresia IIc with severe pulmonary resistance
}

\author{
Koichi Sughimoto, MD, Hiromi Kurosawa, MD, Toshiharu Shin'oka, MD, Masayoshi Nagatsu, MD,
} Shigehiro Morishima, MD, and Takahiko Sakamoto, MD, Tokyo, Japan.

$\mathrm{H}$ igh pulmonary artery resistance $(\mathrm{Rp})$ is one of the risk factors for Fontan completion. Although appropriate pulmonary artery banding (PAB) might decrease the pulmonary artery pressure (PAP), there are some patients who are unable to undergo the Fontan procedure because of high Rp. Anatomic repair with pulmonary autograft for the Björk procedure is one of the options for those patients. On the other hand, total cavopulmonary connection (TCPC) conversion is currently performed for patients with arrythmia or intra-atrial thrombus after atriopulmonary connected Fontan circulation. ${ }^{1-3}$ We recently had a successful experience with extracardiac TCPC conversion after anatomic repair.

\section{Clinical Summary}

A 4-year-old boy with tricuspid atresia (TA) IIc and a ventricular septal defect had undergone an anatomic repair consisting of Jatene, Rastelli, and Björk procedures in 1989. PAB at 19 days of age, a Blalock-Hanlon procedure at 10 months of age, and right pulmonary artery (PA) angioplasty, digital septostomy, and re$\mathrm{PAB}$ at 2 years and 4 months of age had been performed previously. Preoperative catheterization data showed a high mean PAP of $20 \mathrm{~mm} \mathrm{Hg}$, a PA index of 366, a pulmonary artery resistance (Rp) of 5.7 units, and a right ventricular end-diastolic volume of $49 \%$ of the normal value (Table 1). These data suggested that the Fontan procedure was unfavorable at that time, and therefore anatomic repair was planned. The original aorta was implanted between the right atrium (RA) and the right ventricle (RV). The

From the Department of Cardiovascular Surgery, The Heart Institute of Japan, Tokyo Women's Medical University, Tokyo, Japan.

Received for publication May 8, 2004; revisions received June 23, 2004; accepted for publication June 28, 2004.

Address for reprints: Hiromi Kurosawa, MD, Department of Cardiovascular Surgery, The Heart Institute of Japan, Tokyo Women's Medical University, Tokyo, Japan, 8-1 Kawada-cho, Shinjuku-ku, Tokyo, 162-8666, Japan (E-mail: kurosawa@hij.twmu.ac.jp).

J Thorac Cardiovasc Surg 2005;129:684-5

$0022-5223 / \$ 30.00$

Copyright $\odot 2005$ by The American Association for Thoracic Surgery doi:10.1016/j.jtcvs.2004.06.047
TABLE 1. Cardiac catheterization data

\begin{tabular}{lrcccc}
\hline & $\begin{array}{c}\text { PAP } \\
\text { (mm Hg) }\end{array}$ & $\begin{array}{c}\text { PA } \\
\text { index }\end{array}$ & $\begin{array}{c}\text { Rp (dyne } \cdot \mathbf{s} \\
\left.\cdot \mathbf{c m}^{-5}\right)\end{array}$ & $\begin{array}{c}\text { RVEDV } \\
\text { (\% of } \\
\text { normal) }\end{array}$ & $\begin{array}{c}\text { LVEDV } \\
\text { (\%ormal) }\end{array}$ \\
\hline nefore AP & $\begin{array}{r}(20) \\
\text { normal }\end{array}$ \\
After AP & $20 / 13(15)$ & & 5.7 & 49 & 229 \\
Before & $18 / 10(14)$ & 138 & 1.4 & 45 & 196 \\
TCPC-c & & & 1.8 & 73 & 113 \\
\end{tabular}

$\overline{P A P}$, Pulmonary artery pressure; $P A$, pulmonary artery; $R p$, pulmonary artery resistance; RVEDV, right ventricular end-diastolic volume; $L V E D V$, left ventricular end-diastolic volume; $A P$, anatomic repair; $T C P C-C$, total cavopulmonary connection conversion.

coronary arteries (Shaher 1) were translocated to the original PA trunk. After repositioning of the PA as the neoaorta with the Lecompte modification, the RV outflow tract was repaired with a tricuspid Xenomedica conduit (22 mm; Xenomedica AG, Luzern, Switzerland) and connected to the main PA. Jatene, Rastelli, and Björk procedures were completed (Figures 1 and 2). The final central venous pressure (CVP) in the intensive care unit was 19 $\mathrm{mm} \mathrm{Hg}$.

The postoperative course was uneventful. However, repeated atrial flutter and ascites have been recognized since the patient was 14 years old, 10 years after the operation. An unsuccessful catheter ablation, the markedly enlarged RA, and an increased CVP indicated the need for TCPC conversion at 18 years of age, 13 years after the anatomic repair.

After establishment of cardiopulmonary bypass, a bidirectional Glenn (BDG) anastomosis was performed initially. Afterward, the aortic autograft was removed, and the RA-RV route was reconstructed with an enlarged RA wall so that only the coronary venous blood passed through the RV to the PA. Subsequently, the extracardiac TCPC conversion was completed with an interposition of the expanded polytetrafluoroethylene graft $(24 \mathrm{~mm})$ between the right PA and the inferior vena cava. The maze procedure was not performed because of extremely dense epicardial adhesion. The CVP decreased gradually to $13 \mathrm{~mm} \mathrm{Hg}$ in the intensive care unit, and the atrial flutter disappeared entirely at the time of discharge. 


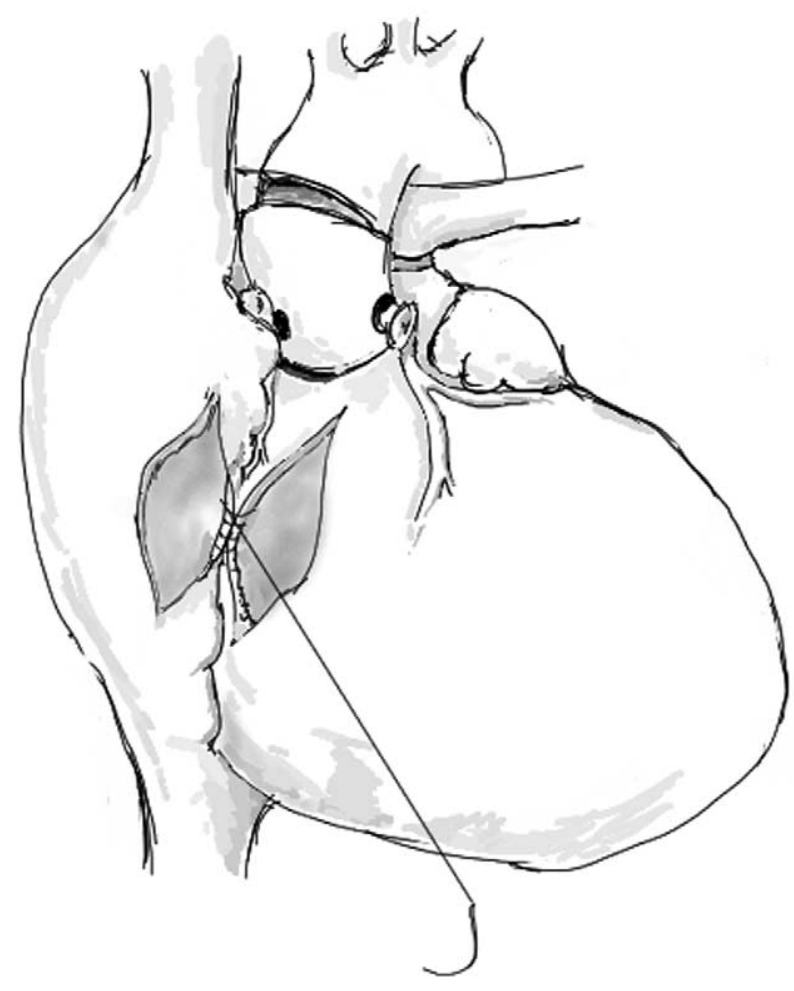

Figure 1. The RA and the RV were opened and resutured. The coronary arteries (Shaher I) were roundly removed. The aortic root was dissected and removed.

\section{Discussion}

Surgical outcome of the Fontan operation has been improved over the last decades, and its indication has increased for patients with a high Rp. Recently, the $\mathrm{BDG}^{4}$ anastomosis has been used as a staged repair for patients with risk factors for Fontan completion, such as PA deformities, atrioventricular valve regurgitation, and high PAP and Rp values. However, even BDG anastomosis might not be feasible for patients with severe Rp, such as those with an $\mathrm{Rp}$ of more than 5 units or a mean PAP of greater than $30 \mathrm{~mm} \mathrm{Hg}$. On the other hand, anatomic repair with the Björk procedure with an autograft has potential indications for TA Ic and TA IIc with high $\mathrm{Rp}$ because the RV would be used as the pulmonic ventricle. ${ }^{5}$ Also, a combination of the anatomic repair and Glenn anastomosis might be useful. We have applied this procedure already for 4 patients (TA Ic, 3 patients; TA IIc, 1 patient). All but 1 patient has had a good postoperative outcome. One other patient had a late death caused by aspiration pneumonia. Unfortunately, in this case the patient had to been converted to TCPC circulation. However, this anatomic repair could maintain adequate cardiac output for more than 10 years and has been an interim procedure for TCPC conversion after adequate decreases in the Rp and PAP. In addition, the 3 other survivors required no anticoagulation therapy and showed excellent results. Therefore, this procedure might be con-

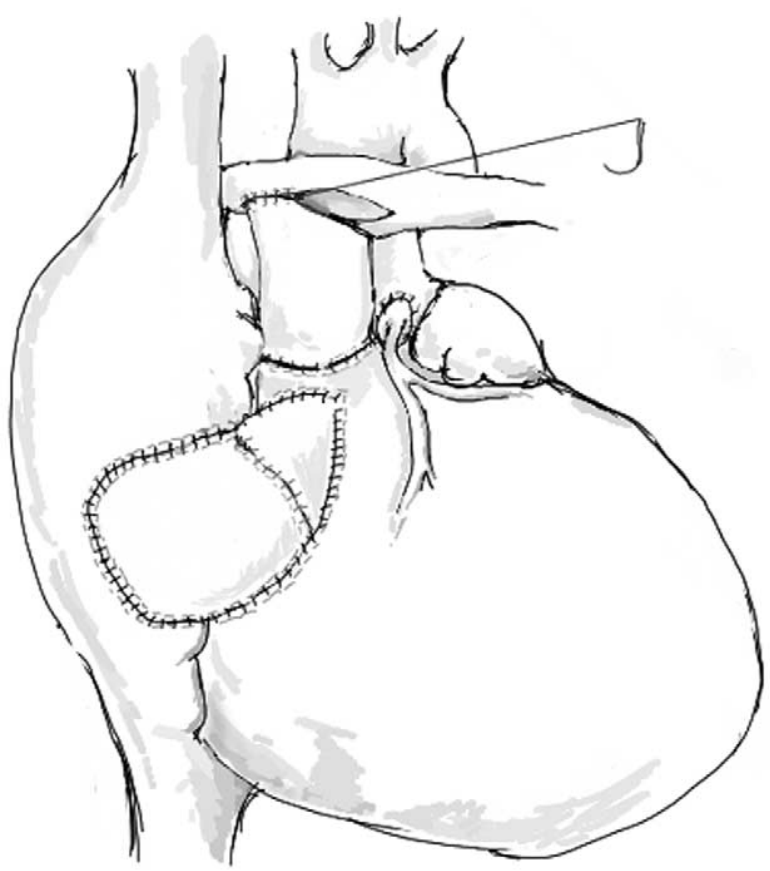

Figure 2. Björk and Rastelli procedures: the autograft of the aortic root was implanted between the $R A$ and the $R V$ and covered with a Xenomedica graft. Jatene procedure: the coronary arteries were transplanted to the original pulmonary artery trunk, and the neoaorta was reconstructed with the Lecompte modification. The RV outflow tract was repaired with a tricuspid Xenomedica conduit.

sidered useful for patients with a high Rp. In this case the implanted aortic valve was extracted, and its calcification and narrowing of the orifice were recognized at the time of TCPC conversion. However, this autograft is an aortic valve, and it is still unclear whether the implanted pulmonary valve would show the same course. Careful observation in the other patients will be required.

\section{References}

1. Varma C, Warr MR, Hendler AL, et al. Prevalence of "silent" pulmonary emboli in adults after the Fontan operation. J Am Coll Cardiol. 2003;41:2252-8.

2. Kreutzer J, Keane JF, Lock JE, et al. Conversion of modified Fontan procedure to lateral atrial tunnel cavopulmonary anastomosis. J Thorac Cardiovasc Surg. 1996;111:1169-76.

3. Kawahira $\mathrm{Y}$, Uemura $\mathrm{H}$, Yagihara $\mathrm{T}$, et al. Renewal of the Fontan circulation with concomitant surgical intervention for atrial arrhythmia. Ann Thorac Surg. 2001;71:919-21.

4. Lamberti J, Spicer R, Waldman JD, et al. The bi-directional cavopulmonary shunt. J Thorac Cardiovasc Surg. 1990;100:22-30.

5. Saito S, Imai Y, Takanashi Y, et al. Fontan procedure after pulmonary artery banding - surgical results and new anatomical repair for tricuspid atresia. Jpn J Thorac Cardiovasc Surg. 1995;43(9):1631-8. 